\title{
Estudo da cicatrização de suturas na bexiga urinária de ratos com e sem a utilização de extrato bruto de Jatropha gossypiifolia L. intraperitoneal ${ }^{1}$
}

\author{
Healing process in bladder suture of rats with and without the administration of \\ intraperitoneal Jatropha gossypiifolia L. gross extract
} \author{
Zacharow Wallbach ${ }^{6}$, José de Ribamar Vale ${ }^{3}$, Nelson Yagushita ${ }^{5}$ \\ 1. Trabalho realizado no laboratório de Pesquisas do Centro de Ciências Biológicas e da Saúde da Universidade Federal do Maranhão \\ 2. Professor do Departamento de Cirurgia da Universidade Federal do Maranhão \\ 3. Médico do Hospital da Universidade Federal do Maranhão \\ 4. Professor Doutor em Cirurgia \\ 5. Aluno de Pós-Graduação - Mestrado \\ 6. Aluno de Pós-Graduação - Doutorado
}

José Maria Ayres Maia ${ }^{2}$, Nicolau Gregori Czeczko ${ }^{4}$, Jurandir Marcondes Ribas Filho ${ }^{4}$, Ulrich Andreas Dietz ${ }^{4}$, Danielle Duck $^{5}$, Carmen Australia Paredes Marcondes Ribas ${ }^{3}$, Eduardo Andrade dos Santos ${ }^{6}$, Eduardo Baptistella ${ }^{5}$, Tatiana

\section{RESUMO}

Introdução: A sutura dos tecidos e sua cicatrização é um dos fundamentos básicos da cirurgia e a procura de substâncias que melhorem este processo é desafio constante. O uso de substâncias retiradas de plantas tem sido testado há muitos anos, contudo sem ainda terem comprovação científica consolidada. Objetivo: Comparar as alterações macroscópicas e histológicas proporcionadas pelo uso do extrato bruto da Jatropha gossypiifolia L. intraperitonial, na cicatrização de suturas realizadas na bexiga urinária de ratos. Métodos: Quarenta ratos da linhagem wistar, adultos, machos foram distribuídos em dois grupos, experimento e controle. Incisão longitudinal de $1 \mathrm{~cm}$ na parede ventral da bexiga e síntese em plano único com pontos separados de poliglactina 910 5-0 (ethicon) foi realizada nos dois grupos. No controle, instilou-se na cavidade peritoneal água destilada na proporção de $1 \mathrm{ml} / \mathrm{kg}$ de peso, enquanto no grupo Jatropha utilizou-se o extrato bruto de Jatropha gossypiifolia L. na proporção de $1 \mathrm{ml} / \mathrm{kg}$, que representava $200 \mathrm{mg} / \mathrm{kg}$ de peso do fitoterápico. Cada grupo foi subdividido em dois subgrupos de 10 animais, sendo estes submetidos à eutanásia no $3^{\circ}$ e $7^{\circ}$ dia pós-operatório. Foi feita análise macroscópica e histológica comparativa entre os subgrupos. Resultados: No $3^{\circ}$ dia foi observada diferença estatisticamente significante nas variáveis inflamação aguda, neoformação vascular e colagenização, sendo a primeira, maior no grupo controle e as duas últimas no grupo Jatropha; no $7^{\circ}$ dia as variáveis inflamação aguda e proliferação fibroblástica apresentaram-se mais intensas, com significado estatístico, no grupo controle. Conclusão: Não se observou efeito favorecedor cicatrizante do extrato bruto da Jatropha gossypiifolia L., intraperitonealmente aplicado, na bexiga urinária de ratos.

Descritores: Jatropha gossypiifolia L. Fitoterapia. Cicatrização de Feridas. Bexiga. Ratos.

\begin{abstract}
Introduction: The suture of tissues and their healing process is one of the basic fundamentals of surgery, and the research on substances which could improve the process is an ongoing challenge. The use of plants has been tested but till nowadays without scientific demonstration. Purpose: To compare the macroscopic and histological alterations done by the use of intraperitoneal Jatropha gossypiifolia L. gross extract, in the healing process of sutures performed on the bladder of rats. Methods: Forty adult, male, Wister rats were distributed into two animal groups. One centimeter longitudinal incision on the bladder ventral wall, and single plane synthesis with separated polyglactine 910 5-0 (Ethicon) stitches was done in all the animals. In the control group an intraperitoneal cavity instillation of distilled water at a ratio of $1 \mathrm{ml} / \mathrm{kg} / \mathrm{weight}$, and a $1 \mathrm{ml} / \mathrm{kg} /$ weight of Jatropha gossypiifolia L. extract for the Jatropha group was done representing $200 \mathrm{mg}$ of the substance. Each group was subdivided into two with 10 animals in each, being submitted to euthanasia on $3^{\text {th }}$ and $7^{\text {th }}$ post-operative days. Comparative histological, macroscopic and statistical analysis were undertaken between the subgroups. Results: Statistical significant difference was observed in the acute inflammation changes, vascular neoformation and bonding on day 3; the first one was greater in the control group, and the latter two greater in the Jatropha group; acute inflammation variables and fibroblastic proliferation presented to be more intense on day 7 , with statistical significance favoring the control group. Conclusion: No favorable healing effect was observed with the administration of single intraperitoneal dose of Jatropha gossypiifolia L. gross extract on the sutures of bladder in rats.

Key words: Jatropha gossypiifolia L. Phytotherapy. Wound Healing. Bladder. Rats.
\end{abstract}




\section{Introdução}

A história das suturas remonta à era pré-cristã datando de 50.000 a 20.000 a.C. e apresenta constatação de interessantes fatos ao longo do tempo.

Citações históricas de Galeno (130 a 211 d.C.) constituem a primeira referência ao uso do fio de categute, mas foi Rhazes (século IX) o primeiro a utilizá-lo em sutura abdominal. Avicenna no século X observou que o linho sofria ruptura na presença de infecção e Ambroise Paré, no século XVI descreve método de aproximação das bordas de feridas da face com fitas. John Hunter no século XVIII relata que a sutura deve ser feita com pontos separados e Joseph Lister (século XIX) propõe a esterilização química dos fios diminuindo a infecção e introduz o fio de categute revestido com ácido crômico ${ }^{1,2,3}$.

A sutura dos tecidos é um dos fundamentos básicos da cirurgia e confunde-se com sua própria história ${ }^{3}$.

A manipulação das feridas, objetivando melhores resultados cicatriciais, vem desafiando os cirurgiões, cujas atitudes se modificaram ao longo dos séculos. Em uma análise panorâmica, identificam-se quatro épocas que se caracterizam por medidas terapêuticas peculiares. Na primeira, que evoluiu até os primórdios do cristianismo, o médico era um mero espectador, e o princípio do tratamento embasava-se na interferência mínima com aplicação de panos limpos e mel sobre o ferimento, aguardando sua resolução à custa do que se entende, atualmente, como cicatrização por segunda intenção ${ }^{4}$.

Estes conceitos permaneceram estáveis até 1586 , quando Ambroise Paré retornou ao princípio da interferência mínima, que foi consubstanciado na seguinte frase: "A natureza fará a cicatrização desde que o médico não atrapalhe sua evolução". Assim como John Hunter, também Willian Halsted e Alexis Carrel aprimoraram técnicas de limpeza minuciosas das feridas e o uso de suturas para aproximação de suas bordas, caracterizando uma segunda fase de evolução.

Uma terceira fase surgiu no século XIX com Semmelweis, Lister e Pasteur, com seus princípios de anti-sepsia para o controle das infecções e, por conseguinte, facilitavam a cicatrização $0^{1,2,3}$.

Finalmente, na época atual, graças às aquisições de conhecimento em metabologia cirúrgica, bioquímica e nutrição, sobreveio uma nova época, na qual se pretende interferir na biologia molecular, influindo na síntese das substâncias responsáveis pelo envolvimento dos fenômenos cicatriciais $^{5}$.

O histórico da descoberta de fármacos originários de plantas data de vários séculos. Shen-Nung (2838-2698 a.C.), importante monarca e considerado o pai da tradicional medicina chinesa, descobriu o uso curativo de muitas plantas e escreveu o Pen-Tsau (O Herbário), um tratado em que menciona o uso de plantas como a papoula, cânhamo, cinamomo e mandrágora. Pedanios Dioscórides (40-90 a.D.), médico grego natural de Anazarba, na Silicia, escreveu um livro intitulado "Matéria Médica", no qual relata o uso de mais de 600 plantas, muitas das quais já não mais existem ${ }^{6}$.

Até meados do século XIX, os animais e as plantas eram as únicas fontes de matéria orgânica ${ }^{7}$.

Em conseqüência da irreparável perda dos conhecimentos da medicina tradicional, aliada ao desconhecimento científico da nossa flora, o conhecimento sobre o emprego das plantas medicinais escapou dos meios científicos e passou, por força do uso, para o domínio popular, gerando os tipos conhecidos pela designação de "doutor raiz", ${ }^{8}$ o qual assumiu a função do verdadeiro farmacognosta e o curandeiro tornou-se o fitoterapeuta, profissionalmente mais conhecido e respeitado pelo grande público do que os raros profissionais de saúde ainda dedicados a esta especialidade médica. Resulta disto que, na maioria das vezes, as plantas são recomendadas conforme as indicações constantes na medicina popular, sem nenhuma avaliação prévia das propriedades terapêuticas a elas atribuídas, nem verificação de sua possível toxidade ${ }^{6}$.

Segundo dados da Organização Mundial de Saúde 9 , 80\% da população utiliza a medicina popular, pois encontra nas plantas um remédio inócuo ou com menos efeitos colaterais que o alopático.

A Jatropha gossypiifolia L. é uma árvore que apresenta folhas e pecíolos roxos, caule jovem com grupos de pêlos glandulares. Um suco leitoso e cáustico é geralmente encontrado nesta planta. Folhas alternadas, palmadas, partes lobadas, grandes, glabra ou pubescentes na parte inferior, pecioladas, de margens ciliadas ou glandulíferas, estípulas, por vezes reduzidas a pêlos, glândulas ou espinhos. Possui fruto seco e esquizocarpo ${ }^{10}$.

Pela citação popular do efeito cicatrizante da Jatropha gossypiifolia L. ${ }^{11}$ e por todos os estudos sobre os seus efeitos terapêuticos e sua ação comprovada em outros setores orgânicos, definiu-se observar este efeito cicatrizante especificamente sobre a cicatrização de feridas na bexiga urinária de ratos com o uso intraperitoneal do extrato bruto de folhas desta Euphorbiacea.

Assim, este estudo tem como objetivo avaliar comparativamente a ação do extrato bruto intraperitoneal das folhas da Jatropha gossypiifolia L. na cicatrização de suturas da bexiga urinária de ratos.

\section{Métodos}

Este estudo foi realizado no Laboratório de Pesquisa do Departamento de Fisiologia e Farmacologia do Centro de Ciências da Saúde da Universidade Federal do Maranhão (UFMA) e foi aprovado pelo Comitê de Ética em Pesquisa da UFMA.

Foram utilizados 40 ratos machos (Rattus Norvegicus albinus, Rodentia mammalia), da raça Wistar, com idade entre 110 e 130 dias de vida, com peso variando entre 200 e 300 gramas no início do experimento, sem doenças prévias e tratados segundo os princípios éticos em experimentação animal.

A coleta da planta foi realizada no bairro de Vila Cafeteira, Paço do Lumiar - Maranhão (Figura 1). A planta foi identificada e classificada no Herbário Ático Seabra da Faculdade de Farmácia da UFMA, cuja exsicata encontra-se 
registrada pelo número 01006.

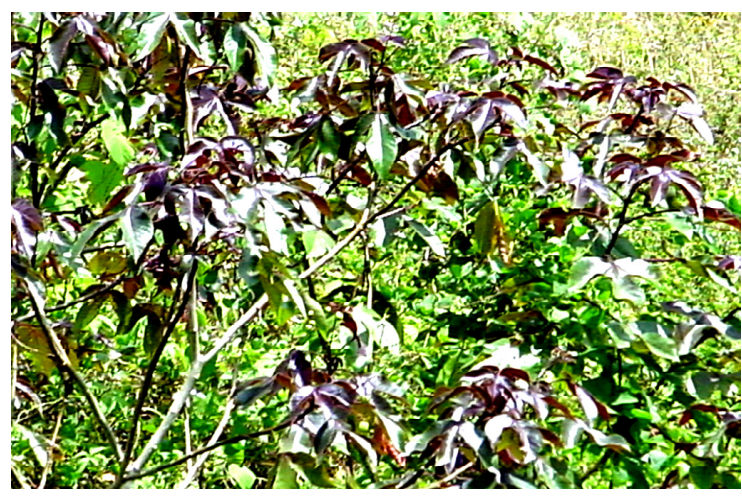

FIGURA 1 - Árvore da Jatropha gossypiifolia L. No local da coleta da amostra

Separaram-se as folhas colhidas da planta. Para confecção do extrato bruto, as folhas foram postas para secar em temperatura ambiente e depois em estufa a temperatura de $45-50^{\circ} \mathrm{C}$, por 24 horas. Em seguida, foram fragmentadas e pulverizadas em moinho elétrico para obtenção de um pó verde. Este foi diluído em solução hidroalcoólica a 70\%, filtrado em filtro de carvão e evaporado para eliminação total do solvente (álcool) em evaporador rotativo a temperatura de $60-65^{\circ} \mathrm{C}$, por 25 minutos. A parte restante foi diluída em água destilada e deionizada, até a concentração de $200 \mathrm{mg}$ do extrato bruto por mililitro da solução.

Os animais foram mantidos no biotério por 15 dias, antes de serem incluídos no estudo, alojados em gaiolas de cinco ratos, em temperatura ambiente, com livre acesso à água potável e ração de origem industrial padronizada.

Os animais receberam anestesia inalatória com ventilação espontânea e identificados com marcas de ácido pícrico compreendendo cabeça, cabeça e dorso, dorso, cauda e sem marca.

$\mathrm{O}$ animal anestesiado foi posicionado sobre um suporte de madeira coberto com campo cirúrgico em decúbito dorsal e a anestesia foi mantida com máscara em sistema semifechado ${ }^{15}$. Realizou-se tricotomia do abdomen e procedeu-se à anti-sepsia da região cirúrgica.

Realizou-se incisão mediana infraumbilical abrindo-se a cavidade abdominal. A bexiga urinária foi dissecada e tracionada com pinça delicada (Figura 2). Após sua exposição, realizou-se a abertura de parede ventral através de incisão de $1 \mathrm{~cm}$ com tesoura delicada.

Realizou-se a sutura da utilizando-se o fio de poliglactina $9105-0\left(\right.$ Vicryl $\left.^{\circledR}\right)$ com agulha cilíndrica de $1,65 \mathrm{~cm}$ (Ethalloy RB-1, Ethicon ${ }^{\circledR}$ ), com quatro pontos separados, totais, cada ponto contendo quatro semi-nós (Figura 3).

Realizou-se a sutura com justaposição das bordas de ferida vesical transfixando-se a parede em cerca de 2 $\mathrm{mm}$ da borda incisional. Nos animais do grupo controle, realizou-se instilação intra-peritonial de água destilada com auxílio de seringa de insulina, no volume de $1 \mathrm{ml}$ por quilo de peso do rato.

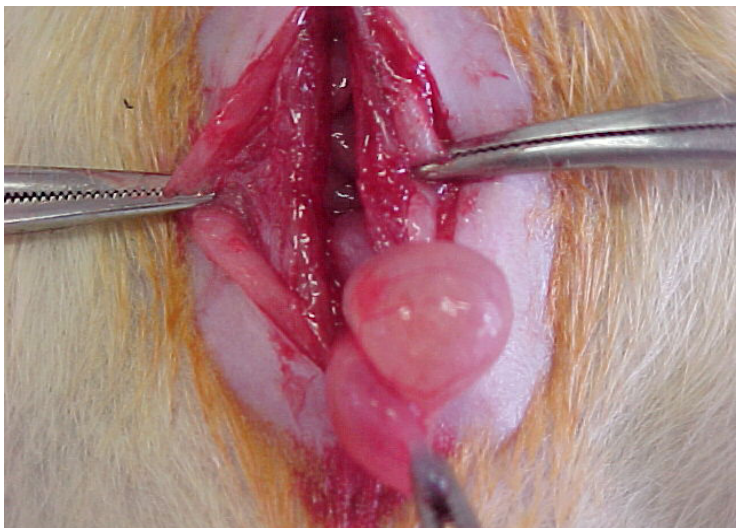

FIGURA 2 - Exposição da bexiga

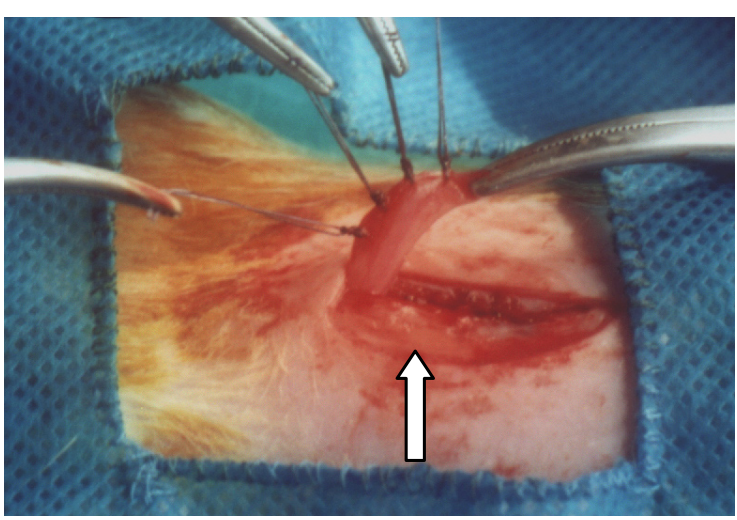

FIGURA 3 - Bexiga urinária suturada com pontos reparados

Os animais do grupo Jatropha receberam a instilação intra-peritoneal do extrato bruto da Jatropha gossypifolia L., na concentração de $200 \mathrm{mg}$ por quilo de peso do animal em dose única. A síntese da parede abdominal foi realizada com sutura continua, peritônio-músculo-aponeurótica, com fio monofilamentar de nylon (Mononylon ${ }^{\circledR}$, Ethicon) 5-0 e agulha cilíndrica de 1,5 cm (Ethipoint J-15, Ethicon $\left.{ }^{\circledR}\right)$. A pele foi aproximada com sutura contínua de fio monofilamentar de náilon 5-0, com agulha cortante de 1,5 cm (Ethipoint SC-20, Ethicon $\left.{ }^{\circledR}\right)$. A ferida foi limpa com solução de cloreto de sódio a $0,9 \%$ e, após, a retirada a máscara com éter sulfúrico. Em seguida, os animais eram recolocados em suas respectivas gaiolas.

Os animais foram examinados diariamente, anotando-se nas fichas de protocolo individual as possíveis alterações comportamentais e da ferida operatória.

Os ratos de cada grupo animal, experimento e controle, foram divididos em dois subgrupos de 10 ratos, tendo sido tanto os ratos do subgrupo controle como o do Jatropha mortos no $3^{\circ}$ e $7^{\circ}$ dia do pós-operatório. Para a eutanásia, colocava-se cada animal sob uma campânula de vidro contendo éter sulfúrico até que ocorresse o óbito.

Após a abertura da cavidade abdominal, promovia-se inventário, buscando a presença de líquidos, aderências peritoneais, aderências entre os órgãos abdominais, especificamente com a bexiga urinária e, quando encontradas, eram 
classificadas segundo escore de adesão de NAIR. Observouse ainda a presença ou não de deiscência da sutura vesical e fístulas urinárias. A bexiga urinária foi retirada junto com as aderências, quando presentes, aberta pela parede dorsal e fixada com pontos a uma placa de isopor, com a mucosa para cima. Cada peça cirúrgica foi acondicionada individualmente em recipientes contendo formol a $10 \%$ e mergulhada. As estruturas aderidas à sutura eram mantidas.

Depois de retiradas do formol e lavadas com água corrente por 15 minutos, os espécimes eram cortadas em três níveis em relação à sutura, desidratadas com álcool, diafanizadas em xilol, submetidas a inclusão com formação dos blocos de parafina e seccionadas com micrótomo a uma espessura média de 4 micra. De cada bexiga urinária, realizaram-se duas lâminas histológicas. A primeira foi corada com hematoxilina-eosina para avaliação global dos cortes de tecido, enquanto a segunda pelo tricrômico de Masson para avaliação das fibras colágenas existentes. A análise dos cortes histológicos foi realizada sem o conhecimento prévio do patologista.

Foram estudados oito campos por lâmina com objetivas de 4,10 e 40 e ocular de 10 . Observaram-se os seguintes critérios: coaptação dos bordos da sutura, neoformação vascular capilar e angiogênese, extensão do infiltrado inflamatório na parede, reação gigantocelular tipo corpo estranho ao redor do fio de sutura, reepitelização dos tecidos, necrose isquêmica, infiltrado inflamatório agudo e crônico, proliferação fibroblástica, e fibrose (colagenização). Cada item foi graduado de 1 a 4, da seguinte maneira: ausente - 1; discreto - 2; moderado - 3; acentuado - 4. Os itens reepitelização e coaptação das bordas da sutura foram graduados em ausente - 1; parcial - 2 e completa - 3. O item extensão do infiltrado na parede foi graduado em até a mucosa - 1; até a submucosa - 2; até a muscular - 3; até a serosa - 4. No item inflamação aguda, foi usado para sua quantificação histológica um escore e um somatório da presença de neutrófilos, congestão vascular e edema. Utilizou-se protocolo de análise histológica, baseado no grau de intensidade, para cada lâmina e realizou-se ao final análise estatística dos dados encontrados

\section{Resultados}

\section{Exame macroscópico}

O peso dos animais no pré-operatório e nas respectivas datas de sacrifício, não apresentou variações significativas. Não se observaram complicações da ferida operatória, tais como hematomas, deiscências, evisceração ou eventração. Observou-se discreta infecção da ferida operatória em dois ratos pertencentes ao grupo Jatropha, e secreção serosa peritoneal de $1 \mathrm{ml}$ em outros dois do mesmo grupo. Nenhum dos animais sacrificados no $3^{\circ}$ ou no $7^{\circ}$ dia pós-operatório apresentou calcificação na linha de sutura ou presença de cálculos na bexiga urinária. Nenhuma bexiga sofreu deiscência da sutura e aderências vesicoepiplóicas (Figura 4) foram encontradas em dois animais do grupo controle e nove do Jatropha.

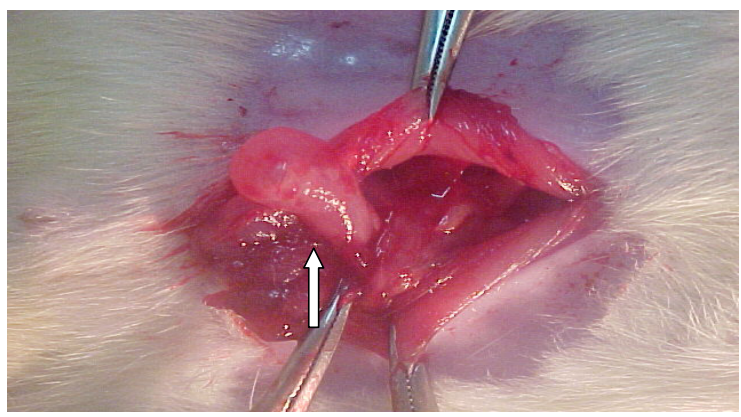

FIGURA 4 - Omento maior aderido a bexiga urinária, grupo Jatropha, no $7^{\circ}$ dia do pós-operatório

\section{Exame microscópico}

Avaliação da coaptação ao nível da anastomosevesical.

Não houve diferença estatisticamente significativa entre os grupos tanto no $3^{\circ}$ como no $7^{\circ}$ dias do pós-operatório.

Avaliação da neoformação vascular capilar e angiogênese

Observando-se a neoformação vascular capilar e angiogênese (Figura 5) no tecido vesical suturado dos animais mortos no $3^{\circ}$ dia pós-operatório dos dois subgrupos, os números mostram que existiu diferença estatística significante no teste aplicado (Mann-Whitney), pois no subgrupo controle todos os animais apresentaram ausência desta variável, enquanto no subgrupo Jatropha três tiveram sua ausência mas em sete ela foi moderada, portanto com maior intensidade no subgrupo Jatropha (Figura 6).

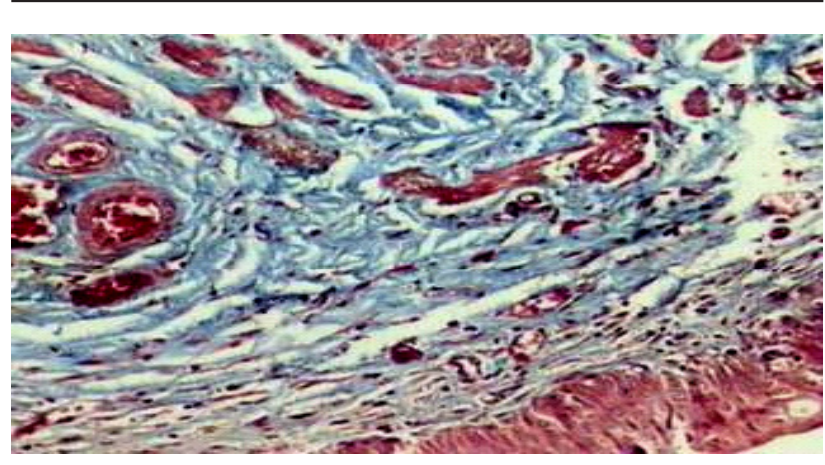

FIGURA 5 - Fotomicrografia mostrando a neoformação vascular capilar e angiogênese moderada com fibrose na área de sutura no $3^{\circ}$ dia pósoperatório (subgrupo Jatropha, coloração H.E., aumento 100x). Nota: Neoformação vascular capilar e angiogênese moderada (seta).

No $7^{\circ}$ dia pós-operatório, a neoformação vascular capilar e a angiogênese não apresentaram diferença significativa entre os subgrupos controle e Jatropha.

$\mathrm{O}$ infiltrado inflamatório na parede vesical da mucosa, submucosa, muscular e serosa, a avaliação reação gigantocelular tipo corpo estranho ao redor do fio de sutura na parede vesical, a reepitelização dos tecidos, a necrose isquêmica 


\begin{tabular}{|l|c|c|c|c|c|}
\hline $\begin{array}{l}\text { Subgrupo } \\
\text { animal }\end{array}$ & Ausente & Leve & Moderada & Acentuada & Total \\
\hline $\begin{array}{l}\text { Subgrupo } \\
\text { controle }\end{array}$ & 10 & 0 & 0 & 0 & 10 \\
\hline $\begin{array}{l}\text { Subgrupo } \\
\text { Jatropha }\end{array}$ & 3 & 0 & 7 & 0 & 10 \\
\hline
\end{tabular}

$\left.\mathrm{p}=0,008{ }^{*}\right)$

FIGURA 6 - Animais dos dois subgrupos, segundo a variável neoformação vascular capilar e angiogênese

na sutura vesical, a reação inflamatória aguda (Figura 7) e a reação inflamatória crônica das túnicas dos ratos mortos no $3^{\circ}$ e no $7^{\circ}$ dia pós-operatório, foi semelhante entre os subgrupos animais

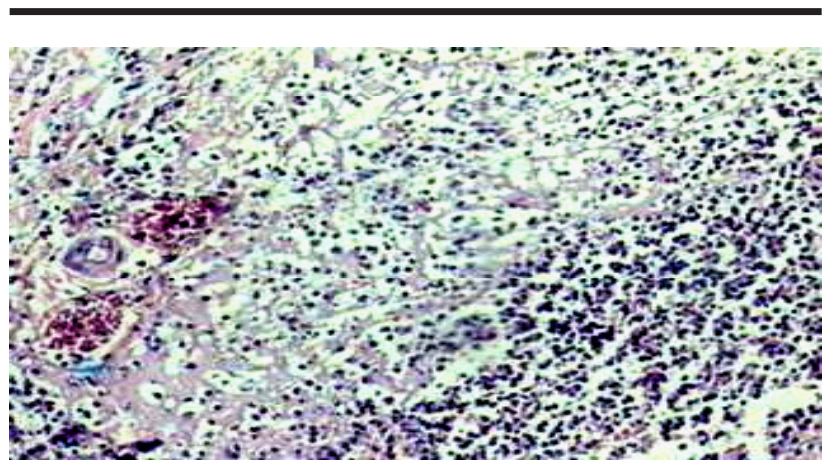

FIGURA 7 - Fotomicrografia com área de inflamação aguda, edema, infiltrado neutrofílico e congestão (subgrupo Jatropha, coloração H.E., aumento 100x). Nota: Área com infiltrado inflamatório agudo (seta)

A proliferação fibroblástica no tecido cicatricial mostrou comportamento diferente entre os subgrupos, em relação ao dia da eutanásia. No $3^{\circ}$ dia não houve diferença estatisticamente significativa, enquanto que no $7^{\circ}$, houve diferença com significância estatística. No presente estudo, nota-se maior intensidade da proliferação fibroblástica do subgrupo controle, em relação ao subgrupo Jatropha no $7^{\circ}$ dia do pósoperatório(Figuras 8 e 9).

\begin{tabular}{|l|c|c|c|c|c|}
\hline $\begin{array}{l}\text { Subgrupo } \\
\text { animal }\end{array}$ & Ausente & Leve & Moderada & Acentuada & Total \\
\hline $\begin{array}{l}\text { Subgrupo } \\
\text { controle }\end{array}$ & 0 & 2 & 8 & 0 & 10 \\
\hline $\begin{array}{l}\text { Subgrupo } \\
\text { Jatropha }\end{array}$ & 0 & 9 & 1 & 0 & 10 \\
\hline
\end{tabular}

$\mathrm{p}=0,008\left(^{*}\right)$

FIGURA 8 - Animais dos dois subgrupos segundo a proliferação fibroblástica no $7^{\circ}$ dia do pósoperatório

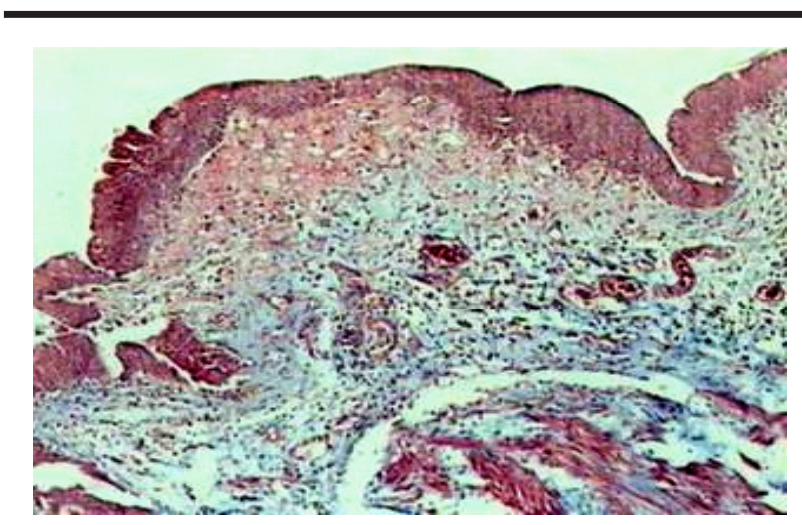

FIGURA 9 - Fotomicrografia com área de moderada proliferação fibroblástica e deposição de colágeno (subgrupo Jatropha $7^{\circ}$ dia do pós-operatório, coloração masson, aumento 100x). Nota: Área com infiltrado inflamatório agudo (seta)

Avaliou-se a intensidade da fibrose determinada pela quantidade de fibras colágenas depositadas na zona de cicatrização (Figura 11). Após análise estatística dos dados, observou-se diferença estatisticamente significativa no $3^{\circ}$ dia do pós-operatório (Figura 10). Este fato não ocorreu em relação aos dados do $7^{\circ}$ dia do pós-operatório.

\begin{tabular}{|l|c|c|c|c|c|}
\hline $\begin{array}{l}\text { Subgrupo } \\
\text { animal }\end{array}$ & Ausente & Leve & Moderada & Acentuada & Total \\
\hline $\begin{array}{l}\text { Subgrupo } \\
\text { controle }\end{array}$ & 9 & 1 & 0 & 0 & 10 \\
\hline $\begin{array}{l}\text { Subgrupo } \\
\text { Jatropha }\end{array}$ & 3 & 7 & 0 & 0 & 10 \\
\hline
\end{tabular}

$\left.\mathrm{p}=0,023{ }^{*}\right)$

FIGURA 10 - Animais dos dois subgrupos, em relação à fibrose da cicatriz (colagenização) no $3^{\circ}$ dia pós-operatório

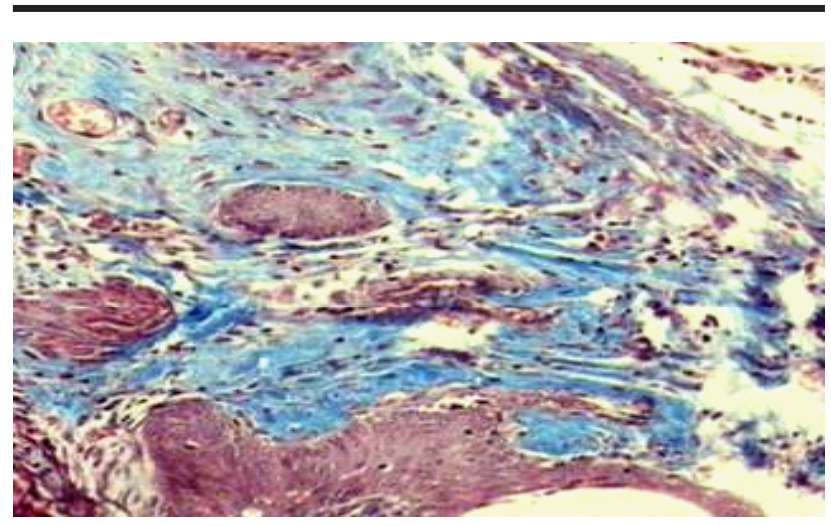

FIGURA 11 - Fotomicrografia com área de fibrose, notando-se deposição de colágeno (subgrupo Jatropha, coloração masson, aumento 100x). Nota: Área de colagenização e proliferação fibroblástica (seta) 


\section{Discussão}

O animal escolhido para este experimento foi o rato da linhagem Wistar, por ser de pequeno porte, de fácil aquisição, padronizado no que tange à idade, sexo, peso, alojamento, alimentação, cuidados de limpeza e manipulação experimental, além de ser resistente às infecções e considerado um bom modelo em suturas vesicais ${ }^{12,13,14}$. O grupo de animais apresentava homogeneidade na amostra e era oriundo no Biotério da Universidade Federal do Maranhão.

Pela experiência da literatura consultada, o animal que melhor se adapta a estudos de sutura da bexiga urinária é o rato. $\mathrm{Na}$ avaliação dos autores deste trabalho, ele mostrouse também ser adequado para experimento na bexiga urinária.

A Jatropha gossypiifolia L., é uma planta que pertence à família das Euphorbiaceas, freqüentemente usada pela medicina popular do Brasil e de outros países, principalmente os latino-americanos e os africanos. Ela é utilizada para diversos fins terapêuticos, sobretudo como anti-hipertensivo e purgativo do trato digestivo e nos tratamentos de hidropisia e reumatismo articular ${ }^{7}$. Apresenta diversas sinonímias, como: batata do téu, jalapão, pião roxo, erva purgante, mamoninha e raiz de téu. A ação cicatrizante do seu látex já foi comprovada ${ }^{10}$. O látex do tronco também se emprega no tratamento tópico de hemorróidas, úlceras e queimaduras e sua ação purgativa é também usada no tratamento do alcoolismo crônico. Estudos realizados com outras Euphorbiaceas ${ }^{15}$ demonstraram a presença de princípios cicatrizantes em diferentes espécies do gênero. Alguns autores ${ }^{16}$, isolaram e identificaram como princípio cicatrizante de Croton palanostigma a L-metil 1-hidroxi2,910-trimetoxi aporfina, outros ${ }^{10}$ nas espécies Croton lechleri e Croton draconoides identificaram o alcalóide taspina como princípio cicatrizante.

Pela facilidade na coleta, estocagem, obtenção e utilização do extrato e por todas as experiências anteriores citadas com a família das Euphorbiáceas, decidiu-se usar a Jatropha gossypiifolia L. no presente estudo. A dose escolhida de $200 \mathrm{mg}$ por $\mathrm{kg}$ de peso foi a preconizada anteriormente ${ }^{11}$. O uso do extrato bruto não alcoólico se deve ao fato do efeito irritativo que o álcool poderia exercer. Escolheu-se a administração intraperitoneal pela comodidade e aplicabilidade.

Neste estudo, utilizou-se a técnica de anestesia inalatória com éter sulfúrico, por ser amplamente utilizada em cirurgia experimental de ratos ${ }^{13,14,15}$.

A seleção do material de sutura foi baseada no fato de que a sutura deve manter sua força tênsil até que a cicatrização ocorra, mas no trato urinário o fio deve ser totalmente absorvido evitando-se assim a formação de cálculos. Os fios absorvíveis podem ser naturais, como o categute, provenientes de submucosa intestinal de animais ou sintéticos, derivados de polímeros, como os de poliglactina. A absorção do fio sintético é realizada por hidrólise, provocando menor reação inflamatória que a absorção do categute que se dá por reação enzimática, interferindo menos no processo de cicatrização. Este fato motivou a escolha do fio de poliglactina para a síntese da bexiga urinária, ao contrário de outros autores, que realizaram sutura vesical com categute ${ }^{12}$.

Optou-se pela sutura na bexiga urinária, que é considerada um dos órgãos menos resistentes do organismo, tendo como característica a síntese de pouco colágeno, com pico no $5^{\circ}$ dia e manutenção até 70 dias, enquanto que o cólon e o estômago, por exemplo, a mantêm até 120 dias 17. Exames da bexiga mostraram formação de cicatriz sem regeneração muscular, portanto sua cicatrização ocorre por síntese, deposição e remodelamento do colágeno formando a cicatriz ${ }^{18}$

Para a realização da vesicotomia, optou-se pela incisão simples da parede vesical, sem retirada de fragmento, obtendo-se uma incisão mais regular ${ }^{13,14,19}$ em função de que o interesse deste estudo era a avaliação somente do aspecto cicatricial. Escolheu-se a sutura em plano único com pontos separados por ser a mais usada neste procedimento ${ }^{20}$.

Apenas foi observada discreta presença de infecção de parede na sutura de dois animais do grupo controle e não se verificou nenhum óbito no período da observação. Alguns autores $^{13}$ tiveram dois óbitos por evisceração, outros ${ }^{19}$ relatam em seu experimento o óbito de três ratos por causas desconhecidas. Outros autores não relatam óbitos de animais em seus trabalhos ${ }^{4}$.

Para estudar comparativamente os dois grupos tomandose como base a qualidade de sua cicatrização, escolheu-se a avaliação intergrupal no $3^{\circ}$ e $7^{\circ}$ dias do pós-operatório. Este período representa a fase inicial e intermediária da cicatrização, de modo que se esperava um processo inflamatório intenso e indícios sobre a resistência mecânica na sua relação direta com o tipo de técnica utilizada. No estudo histológico destes dias em geral, a cicatrização no trato urinário mostrase eficaz e segura, e pode-se obter resultados que tornam possível tirar conclusões definitivas. Períodos maiores de avaliação pós-operatória foram rejeitados, em razão de que, no processo avançado de cicatrização, haveria tendência dos parâmetros avaliados aproximarem-se nos dois grupos ${ }^{14}$.

Neste estudo, encontrou-se aderência de epíploon em 11 das 40 bexigas urinárias, sendo duas no grupo controle e nove no grupo Jatropha, o que também já foi demonstrado em outros estudos ${ }^{18}$ utilizando outros fios e selantes (cianoacrilato). Mesmo assim, e nas condições assemelhadas, há relatos da inexistência dessas aderências ${ }^{13}$. Elas foram firmes e frouxas, segundo escore de adesão de Nair (1992) em proporções não diferentes das citadas na literatura ${ }^{13}$.

Foi encontrada secreção serosa peritoneal em dois ratos operados do grupo Jatropha, sem que, no entanto, tenha havido reação inflamatória peritoneal.

Não se encontrou cálculo urinário em nenhuma das bexigas operadas, devido, provavelmente, ao pouco tempo de observação utilizado neste trabalho. Steward ${ }^{19}$, em pesquisa com 120 ratos, comparando os fios de polidioxanome, poliglactina e categute cromado em sutura vesical e sacrificando os animais em uma semana, um mês, três meses e seis meses, encontraram incidência baixa de litíase, sem significância estatística, enquanto que, no grupo em que foi utilizado o polidioxanone, não encontraram cálculos.

A avaliação microscópica identifica os parâmetros celulares do reparo cicatricial . A coloração pela hematoxilinaeosina foi adotada, por tratar-se de corante universal, usado 
rotineiramente para avaliações em estudos histológicos, além de ser método de coloração simples e barato, adequado para quantificar e identificar os elementos celulares envolvidos no processo cicatricial. O tricrômico de Masson foi a coloração utilizada para avaliar especificamente a proliferação fibroblástica e a colagenização, pela sua especificidade em evidenciar estes parâmetros ${ }^{1}$.

A reparação é o processo pelo qual células destruídas são substituídas por células vivas. Somente algumas células do homem são capazes de regeneração e, mesmo assim, sob condições especiais. A substituição das células destruídas envolve, portanto, proliferação de tecido conjuntivo, com a formação de cicatriz fibrosa. Deste modo, restaura-se a continuidade anatômica do tecido, mas de modo imperfeito, substituindo células funcionantes por tecido conjuntivo não especializado. O processo de reparação é sempre precedido de processo inflamatório. A inflamação é a reação dos tecidos a todas as formas de lesão, envolvendo respostas vasculares, neurohormonais, humorais e celulares no local da lesão. $\mathrm{O}$ processo inflamatório destrói, dilui ou engloba o agente agressor e abre caminho para reparação. A reparação que se inicia logo após o processo inflamatório é caracterizada pela formação de colágeno, que é responsável pela força e integridade de todos os tecidos. Assim, a força e a integridade do tecido de reparação residem no tipo de fibra colágena sintetizada e na quantidade de ligações cruzadas. O material de sutura altera o processo normal de cicatrização por diversos fatores. O primeiro deles é o trauma da inserção da agulha e a aproximação das bordas, causando tensão seguida de isquemia, com desvitalização dos tecidos. Em segundo lugar, ocorre uma reação do tecido ao material de sutura, que desencadeia, como corpo estranho que é, autólise tecidual e acompanhada de reação inflamatória que depende do diâmetro e da quantidade dos fios que permanece nos tecidos. O terceiro fator importante são as propriedades físico-químicas do material de sutura.

Na coaptação das bordas da mucosa, muscular e serosa, inflamação crônica, necrose isquêmica, reação gigantocelular do tipo corpo estranho ao redor do fio de sutura, reepitelização, extensão do infiltrado na parede não foram encontradas diferenças estatísticas na comparação dos dois subgrupos no $3^{\circ}$ e $7^{\circ}$ dia do pós-operatório. No $3^{\circ}$, observaram-se características diferentes entre os subgrupos controle e Jatropha em três parâmetros: inflamação aguda mais acentuada no subgrupo controle, apresentando significância estatística ( $\mathrm{p}=0,008)$; neoformação vascular capilar que, no subgrupo Jatropha ,foi mais acentuada, também com significância estatística $(\mathrm{p}=0,008)$; fibrose mais acentuada também no sub grupo Jatropha, com significância estatística $(p=0,023)$. No $7^{\circ}$ dia do pós-operatório, houve diferença com significância estatística $(\mathrm{p}=0,008)$ nas variáveis inflamação aguda e proliferação fibroblática entre os dois subgrupos, sendo mais acentuada no subgrupo controle. Os resultados das análises estatísticas levam a concluir que houve diferença na cicatrização, comparando-se os dois grupos, sendo mais intensa no grupo controle e que o extrato bruto da Jatropha gossypiifolia L., intraperitoneal, na dose usada, não teve efeito favorecedor na cicatrização da bexiga urinária de ratos Wistar.
O presente estudo incentiva a continuidade desta linha de pesquisa, talvez com maiores doses e prazos, abrindo espaço para propostas de experimentos com plantas medicinais e pesquisas de origem fitoterápica sobre a Jatropha gossypiifolia L. ou outras plantas da nossa flora, já que o Brasil é um grande depositário desta matéria-prima.

\section{Conclusões}

Não se observou efeito favorecedor cicatrizante do extrato bruto da Jatropha gossypiifolia L., intraperitonealmente aplicado, na bexiga urinária de ratos.

\section{Referências}

1. Nathan H. The search for the ideal suture. Int Surg. 1972;57: 26-9.

2. Mackenzie D. The History of Suture. Med Hist.1973;8: 158-68.

3. Fagundes DJ, Kharmandayan P. O fio cirúrgico. Acta Cir Bras. 1991;6:177-81.

4. Polk Jr. HC, Lopez-Mayor JF. Postoperative wound infection: a prospective study of determinant factors and prevention. Surgery 1969; 66: 97-103.

5. Torti FM, Dieckmann B. A macrophage factor inhibits adipocty gene expression: a in vitro model of cachexia. Science 1985; 229: 867- 9.

6. Matos FJA. Introdução à fotoquímica experimental. Universidade Federal do Ceará. Fortaleza: UFC; 1997.

7. Alzugaray D, Alzugaray C. Plantas que curam. São Paulo: Três alta, 1995

8. Landmann J. As medicinas alternativas: mitos, embustes ou ciência. Rio de Janeiro: Guanabara Koogan;1989.

9. Elisabetsky E. Pesquisas de plantas medicinais. Ciên. Cult. 1987; 39: 697-702.

10. Vaisberg A, Tello V, Zavaleta A, Villegas L, Salas M, Fernandez I, Salas J. Actividad cicatrizante del látex de Jatropha curcas. Rev Biol Trop.1994; 42(1/2): 323-6.

11. Abreu TRA. Estudo farmacológico da Jatropha gossypiifolia L.[Monografia]. São Luis: Centro de Ciências da Saúde - Universidade Federal do Maranhão; 1992.

12. Edlich RF, Panek PH, Rodeheaver GT, Kurtz LD, Edgerton MT. Surgical sutures and infection : A biomaterial evaluation. J Biomed Mater Res. 1974; 5: 115-26.

13. Biondo-Simões MLP, Sech M, Adur RC, Marques LO, Corbellini M, Canalli LS, Veronese M, Cabrera P, Vaz LI. A comparative study of the performance of catgut and poliglecaprone 25 sutures in rat abdominal walls contaminated or not. Acta Cir Bras.1997; 12: 163-8.

14. Vargas J A. Estudo comparativo entre os fios de poliglecaprone 25 e categute cromado em bexiga de ratas. [Tese]. São Paulo: Universidade Federal de São Paulo. Escola Paulista de Medicina; 1999.

15. Brito MVH, Brito NMB, Cruz MMS, Oliveira VB, Silva TTB, Reis JMC. Estudo histológico da bexiga de ratos após administração de óleo de copaíba. Rev Para Med.1999;13: 20-4. 
16. Miranda L. Alcaloides de Croton palanostigma Klotzsch (Sangre de grado). [Tesis de Magister en Quimica] . Peru: Universidad Peruana Cayetano Heredia; 1976.

17. Edlich RF, Rodeheaver GT, Thacker J . Considerations in the choice of sutures for wound closure of the genitourinary tract. J Urol. 1987; 137: 373-9.

18. Hasting JC, Van Winkle W, Barker E, Hines D, Nichols W. The effect of suture materials on healing wounds of the bladder. Surg Gynecol Obst.1975; 140: 933-6.
19. Stewart DW, Buffington PJ, Wacksman J. Suture material in bladder surgery: a comparison of polydioxanone, polyglactin, and chromic catgut. J. Urol 1990;143:12613.

20. Bartone FF, Shires TK. The reaction of kidney and bladder tissue to catgut and reconstituted collagen sutures. Surg Gynecol Obstet. 1969;128:1221-5.
Correspondência

José Maria Ayres Maia

Hospital Universitário Presidente Dutra

Rua Barão de Itapary, 227 - Centro - São Luis-MA

CEP: 65020-070

Tel: (98) 2109-1000
Conflito de interesse: nenhum Fonte de financiamento: Capes

Recebimento: 26/01/2005

Revisão: 28/05/2005

Aprovação: 03/05/2006

\section{Como citar este artigo}

Maia JMA, Czeczko NG, Ribas-Filho JM, Dietz UA, Duck D, Ribas CAPM, Santos EA, Baptistella E, Wallbach TZ, Vale JR, Yaguishita N. Estudo da cicatrização de suturas na bexiga urinária de ratos com e sem a utilização de extrato bruto de Jatropha gossypiifolia L. intraperitoneal. Acta Cir Bras. [periódico na Internet] 2006; Suppl 2:23-30. Disponível em URL: http://www.scielo.br/acb

Figuras coloridas disponíveis em http://www.scielo.br/acb 